\title{
Preferences for Exercise as a Treatment for Depression
}

\author{
Andrew M. Busch ${ }^{1,2}$, Joseph T. Ciccolo ${ }^{3}$, Ajeng J. Puspitasari², Sanaz Nosrat ${ }^{3}$, James W. \\ Whitworth $^{3}$, and Matthew Stults-Kolehmainen ${ }^{3}$ \\ ${ }^{1}$ The Miriam Hospital, 164 Summit Ave., Providence, RI 02906 \\ ${ }^{2}$ Warren Alpert Medical School of Brown University, 222 Richmond St., Providence, RI 02903 \\ ${ }^{3}$ Teachers College, Columbia University, 525 W. 120 St., Box 199, NYC, NY 10027
}

\begin{abstract}
Depression is a leading cause of disability worldwide, but most depressed individuals do not receive treatment. There is now significant support for physical exercise as an effective alternative treatment for depression, which may be more accessible than traditional psychiatric treatments. Little is known about preferences for exercise as a depression treatment.
\end{abstract}

Method-A total of 102 individuals (50\% female, mean age $=39$ ( $\mathrm{SD}=13.1$; range: $18-62$ ), 83\% Caucasian) with likely major depression completed an online survey of exercise for depression treatment preferences and barriers to increased exercise. Results are reported by gender due to well established gender differences in exercise preferences.

Results-Both genders reported a high level of interest in an exercise for depression program. On average, participants preferred an individual walking program that was coached, asked them to engage in one longer bout multiple times per week, and was provided in home. However, there was significant variability within and between genders. Lack of motivation, mood, and fatigue were reported as barriers to exercise by the majority of participants of both genders.

Conclusion-The majority of those with depression have interest in an exercise for depression program, but symptoms of depression are seen as significant barriers. Future studies should use these results to design exercise for depression programs. The variability and gender differences in our results suggest that flexible programs may be needed.

Depression is a leading cause of disability worldwide (Mathers, Fat, Boerma, \& World Health Organization., 2008). Current global estimates of the lifetime prevalence of a major depressive episode are between $11.1 \%$ and $14.6 \%$ (Kessler \& Bromet, 2013). In the United States (US), the prevalence is much higher with lifetime estimates of $19.2 \%$ (Kessler \& Bromet, 2013). Women are twice as likely to suffer from depression compared to men (Kessler, 2003; Mathers, et al., 2008), but women are more likely to seek traditional

Corresponding Author: Andrew M. Busch, PhD, Assistant Professor (Research), Centers for Behavioral and Preventive Medicine, Brown Medical School, Coro Bldg West, Suite 309, 164 Summit Ave., Providence, RI 02906, Andrew_busch@ brown.edu, 401-793-8189.

Publisher's Disclaimer: This is a PDF file of an unedited manuscript that has been accepted for publication. As a service to our customers we are providing this early version of the manuscript. The manuscript will undergo copyediting, typesetting, and review of the resulting proof before it is published in its final citable form. Please note that during the production process errors may be discovered which could affect the content, and all legal disclaimers that apply to the journal pertain. 
psychiatric treatments for depression (Addis \& Mahalik, 2003). The under-utilization of mental health services is recognized as a global health issue (Andrade et al., 2014). The percentage of people meeting criteria for major depression but not receiving treatment is 53.9\% globally and $72.3 \%$ in the US (Kohn, Saxena, Levav, \& Saraceno, 2004). Among those who attempt to seek treatment, barriers include cost (e.g., high co-pays) and access (e.g., geographical, long wait lists due to limited number of providers; Mojtabai et al., 2011; Prins, Verhaak, Bensing, \& van der Meer, 2008). However, emotional barriers including embarrassment, fears of social consequences (i.e., stigma) or an unwillingness to discuss personal matters with a provider also prevent treatment seeking (Mohr et al., 2006). As such, interventions that reduce depression symptoms, but minimize logistical and emotional barriers to depression treatment could have significant public health implications.

Physical exercise may be just such an intervention, given its low barriers to entry (e.g., low cost and ease of access) and its demonstrated ability to meaningfully improve depression symptoms (Cooney, Dwan, \& Mead, 2014; Ekkekakis, 2015). For example, several metaanalyses have compared the effect of exercise on major depression and depression symptoms to a no-treatment, placebo, or active control condition (e.g., stretching). Results consistently show a positive effect with a range of moderate (Cooney et al., 2013) to large clinical effect size differences (Lawlor \& Hopker, 2001; Rethorst, Wipfli, \& Landers, 2009).

Importantly, preferences for the structure of exercise (e.g., activity, setting, intensity, etc.) and perceived and barriers to exercise vary widely across populations (Jones \& Courneya, 2002). Unfortunately, exercise is often prescribed in a "one size fits all" fashion (Booth, Bauman, Owen, \& Gore, 1997). Consequently, poor exercise program initiation, commitment, and retention may be a result of a mismatch between the clinician prescribed exercise program and the needs, wants and beliefs of the target population. Uptake and completion of an exercise referral are significantly higher if the referral is for a physical problem rather than a mental health problem (Crone, Johnston, Gidlow, Henley, \& James, 2008), suggesting that standard referrals may be unacceptable to those with depression and other mental health problems.

To date, research has primarily focused on general physical activity and exercise engagement preferences among distressed individuals or patients with mental illness (Carpiniello, Primavera, Pilu, Vaccargiu, \& Pinna, 2013; Ussher, Stanbury, Cheeseman, \& Faulkner, 2007). However, given the growing interest in exercise as a treatment for depression, there is surprisingly little work regarding preferences for exercise specifically as a treatment for depression. To our knowledge, there is one qualitative study that directly addresses this issue (Searle et al., 2011). There are also two studies which enrolled many depressed patients, but both focused on preferences for exercise within the context of intensive substance abuse treatment (Abrantes et al., 2011; Stoutenberg, Warne, Vidot, Jimenez, \& Read, 2015).

Thus, there is a gap in the literature regarding evidence to inform exercise programs designed specifically as treatments for depression. The aim of the current investigation is to address this gap by assessing the following among a sample of currently depressed individuals: 1) rates of willingness to participate in an exercise program targeting mood, 2) 
preferences for the content and structure of an exercise for depression treatment, 3) perceived barriers to increasing exercise, and 4) any gender differences in the above aims.

\section{Method}

\section{Participants}

We enrolled participants that 1 ) scored $\geq 10$ on the PHQ-8 (Kroenke, Spitzer, \& Williams, $2001)$; 2) endorsed at least one of the two cardinal symptoms of depression (i.e., indicated $\geq$ 1 on the depressed mood and/or the anhedonia items on the PHQ-8);3) were 18-65 years old; 4) could read English fluently; and 5) lived in the US. All recruitment occurred online through a contract with Qualtrics ${ }^{\circledR}$, a third-party online survey company that maintains "panels" of potential research participants. The contract specified a 50/50 gender split. All panel members had expressed interest in being recruited for online research and had provided their email to Qualtrics ${ }^{\circledR}$ to allow invitations to participate in specific studies. Qualtrics ${ }^{\circledR}$ sent out email solicitations for the current study to existing panels of US residents. All procedures were approved by the Miriam Hospital Institutional Review Board.

A link to the eligibility screener was sent to approximately 1200 individuals. A total of 364 individuals viewed the eligibility screener, which included the PHQ-8 and questions for other inclusion criteria listed above. Two hundred and forty four individuals either did not complete the screener or did not qualify based on the screener questions. The remaining 120 individuals who qualified based on the screener, were provided more detailed information about the study, and asked to complete the online consent form. There were 4 individuals who decided not to participate after reading the consent form. The resulting 116 individuals answered at least one question on the survey, and 107 completed the survey. We excluded 5 individuals who completed the survey because they provided clearly invalid or contradictory responses answers to the majority of items (e.g., straight line responding, gibberish responses to open-ended questions). Thus, final data analyses were based on responses from 102 participants.

Participants who completed the survey received 35 "merchant points" that were delivered directly to their Qualtrics ${ }^{\circledR}$ panel account within two weeks of participation. The account was not specific to this study (i.e., participants accumulated points from other studies as well). Participants could exchange the merchant points for cash payments, gift cards to retailers, or airline miles. The full survey took approximately 15 minutes to complete.

\section{Measures}

We modeled our measurement on a similar study assessing preferences regarding exercise (Abrantes, et al., 2011), with adjustments to reflect our depressed population.

Demographics-Participants reported age, gender, income, race/ethnicity, employment status, education level, sexual orientation, and physical medical conditions that limit exercise. Participants also reported if they had ever received psychiatric treatment (i.e., counseling or medication) for depression and if they were currently in depression treatment. 
Current Exercise Behavior-Participants were asked if they currently engaged in any type of exercise. A modified version of the Modifiable Activity Questionnaire (Pettee Gabriel, McClain, Schmid, Storti, \& Ainsworth, 2011) was used to assess activity type and metabolic equivalents (METs) were calculated. The number of sessions per week and the duration of each session were assessed. Participants were categorized as completely sedentary, insufficiently active ( $<500$ METS/week), or sufficiently active ( 2500 METS/ week) according to the national physical activity guidelines (Garber et al., 2011).

\section{Willingness to participate in an exercise program targeting mood-}

Participants were asked if they were interested in an "an exercise program designed to improve mood in persons with depression" and answered "yes", "maybe", or "no". We report willingness to participate in an exercise for depression program by gender, current engagement in depression treatment, presence of a physical medical condition that limits exercise, and level of current exercise activity.

\section{Preferences for the content and structure of an exercise for depression} program-All participants that reported some interest in an exercise for depression program (i.e., responded "yes" or "maybe") were asked questions regarding preferences for content and structure of such a program. Participants reported on preferred location (e.g., home, gym), social environment (alone or group), coaching status (coached or uncoached), coaching format, frequency, duration, and intensity. Participants also reported the type of exercise they would most prefer when engaging in a program specifically designed for depression. The list of activity types from the Modifiable Activity Questionnaire was provided (e.g., aerobic dance, soccer, walking, weight lifting, etc.), with an open option to list any preferred activity not listed.

Barriers to Exercise-Participants were also asked to review a list of 12 barriers to increasing exercise (see list in Table 2) and endorse all that were applicable. We specifically included symptoms of depression as potential barriers (e.g., mood, motivation, fatigue).

Data Analysis-All analyses were conducted in SPSS V18. We chose (a priori) to focus on gender differences in the above variables because of well established gender differences in exercise preferences.

\section{Results}

\section{Demographics}

The sample was $50 \%$ female with a mean of age of 39.4 ( $\mathrm{SD}=13.1$; range: $18-62)$ years. Racial distribution was 83.3\% Caucasian, 6.9\% African American, 3.9\% Asian, 2.9\% multiracial, $1.0 \%$ American Indian/Alaskan Native, and 1.0\% Native Hawaiian/ Pacific Islander (1.0\% refused). 7.8\% reported Hispanic/Latino ethnicity. Median household income was $\$ 24,060$ per year $(\mathrm{IQR}=\$ 39,600)$ and $91.2 \%$ of the sample completed high school. The sample was $38.2 \%$ married or living with a romantic partner and $77.5 \%$ heterosexual. A physical medical condition that limited exercise was reported by $38.2 \%$ of the sample. The mean PHQ-8 score was $16.8(\mathrm{SD}=4.1$; range $=10-24)$. Most $(83.3 \%)$ of the sample had 
received treatment for depression during their lifetime, and $62.7 \%$ were currently receiving treatment for depression.

\section{Current Exercise Behavior}

Based on national physical activity guidelines, $22.5 \%$ of participants reported no exercise, $49.0 \%$ reported insufficient activity, and $28.4 \%$ reported being sufficiently active.

\section{Willingness to Engage in Exercise as a Treatment for Depression}

When asked about willingness to participate in "an exercise program designed to improve mood in persons with depression", $61.8 \%$ of participants answered "yes", $34.3 \%$ answered "maybe", and 3.9\% answered "no". Rates of willingness to participate were similar among those currently in depression treatment (64.1\% yes, $32.8 \%$ maybe) and those not currently in depression treatment ( $57.9 \%$ yes, $36.8 \%$ maybe). Rates of willingness to participate were also similar among men (60.8\% yes, $31.4 \%$ maybe) and women (62.7\% yes, $37.3 \%$ maybe). However, willingness to participate significantly differed between those who reported a physical medical condition limited their exercise ( $46.2 \%$ yes, $48.7 \%$ maybe) and those who did not (71.4\% yes, $25.4 \%$ maybe; Mann-Whitney $U=921.0, p=.01$ ). Willingness to participate also differed significantly by current activity level, with those more active being more willing to participate (i.e., those sufficiently active $75.9 \%$ yes, $20.7 \%$ maybe; those insufficiently active $64.0 \%$ yes, $32.0 \%$ maybe; those completely sedentary $39.1 \%$ yes, $56.5 \%$ maybe; Spearman $\mathrm{r}=.25, p=.01$ ).

\section{Preferences for Structure and Content of Exercise for Depression Program}

The 98 participants ( $96.1 \%$ of total sample) who reported some interest in participating in an exercise for depression program (i.e., responded yes or maybe) were also asked questions regarding preferences for content and structure of such a program. These preferences are presented by gender in Table 1 .

Among those who preferred coaching, there were significant gender differences in type of coaching preferred $\left(\chi^{2}(2, N=49)=6.48, p=.04\right)$, with men showing a preference for in person or video coaching and women more open to text or email coaching. There was a marginally significant gender difference in preference for intensity $\left(\chi^{2}(3, N=98)=6.99, p\right.$ $=.07$ ). When examined specifically as set intensity vs. graded intensity (i.e., increasing from low to high over a period of time), women preferred graded intensity more often than men $\left(\chi^{2}(1, N=98)=4.08, p=.04\right)$.

Walking (30.6\%), weight lifting (16.3\%), yoga (9.2\%), and dance (9.2\%) were the most preferred forms of exercise. The other forms of exercise were all endorsed by less than $5 \%$ of participants. Walking was the most commonly preferred form of exercise among both genders. Men preferred weight lifting at more than double the rate of women $\left(\chi^{2}(1, N=98)\right.$ $=3.31, p=.07)$, while women preferred yoga significantly more than men $\left(\chi^{2}(1, N=98)=\right.$ $5.39, p=.02)$. 


\section{Perceived Barriers to Exercise}

Perceived barriers to exercise by gender are presented in Table 2. Lack of motivation, mood, and fatigue were all reported by the majority of participants of both genders. Marginally significantly more men reported "Lack encouragement and support from family/friends" as a barrier $\left(\chi^{2}(1, N=102)=3.46, p=.06\right)$.

\section{Discussion}

This is the first study to assess the willingness to engage in an exercise-based treatment for depression, as well as the preferred exercise type and program content of such a treatment. The vast majority of participants were willing to at least consider participation in an exercise program designed to improve mood, indicating that such a treatment is generally acceptable by persons with depression. Interestingly, willingness was high even among those currently in depression treatment, suggesting that this population also views exercise as a viable adjunct to psychiatric treatment for depression. While willingness was somewhat lower among those with a physical medical condition limiting their exercise, the majority of these participants still expressed interest in participating in such a program ( $46 \%$ answered yes, $49 \%$ answered maybe). This is an important finding given the high rates of co-occurring depression and physical disability (Smith et al., 2014). An unexpected finding was that the participants with higher levels of current physical activity were more interested in an exercise for depression program. This suggests that even those already active see value in a program specifically designed for depression treatment and that those who are sedentary may need motivational interventions prior to starting an exercise for depression program.

Overall, the results show that participants prefer an exercise-based treatment for depression program that 1) is coached, 2) 30-60 minutes in length, 3) occurs multiple times per week, 4) is provided in the home, and 5) is provided on the individual level (i.e., not group treatment). There was no clear overall preference regarding length, intensity, or type of coaching. Some significant gender differences were observed. Specifically, women preferred graded intensity over a set intensity. Men preferred in-person and video coaching more than women and women preferred text/email coaching more than men, which may represent gender difference in willingness to be observed during exercise.

Walking was the most preferred form of exercise for an exercise-based depression program, followed by weight lifting, yoga, and dance. Men preferred weight lifting marginally more than women, while women preferred yoga significantly more than men. These preferences are consistent with previous work regarding preferences of substance abusing populations (Abrantes, et al., 2011; Stoutenberg, et al., 2015). The high variability in preferred form of exercise and preferred structure suggest that flexible programs or multiple varied referral options are needed to increase acceptability of referrals to exercise as a depression treatment. Such individualized exercise prescriptions and programs have been successfully implemented with other chronic disease populations (Durstine, American College of Sports Medicine., \& American College of Sports Medicine., 2009). However, the minimum intensity needed to affect depression also warrants consideration, as some data suggests that at least moderate intensity is required (Dunn, Trivedi, Kampert, Clark, \& Chambliss, 2005). 
Our results indicate that lack of motivation, low mood, and fatigue are the most common barriers to increasing exercise among those with depression. Lack of motivation and fatigue have also been identified as barriers in those with depression (Searle, et al., 2011) and among depressed substance users (Abrantes, et al., 2011; Stoutenberg, et al., 2015). It is important to note that all three of these barriers are symptoms of depression, suggesting that exercise-based depression treatment programs will need strategies to overcome these specific barriers.

These findings are not without limitations. First, the sample size is somewhat small and there is an underrepresentation of some racial/ethnic groups (e.g., Hispanics/Latinos). Second, all the data is self reported, and questionnaires, rather than clinical interviews were used to classify participants as depressed. There are also well established limitations with self-reported physical activity levels, thus the activity levels reported above may be higher than actual values (Sallis \& Saelens, 2000). Third, there may be selection bias given that all participants were recruited through Qualtrics. Forth, only data on perceived willingness to participate in an exercise-based depression treatment program was collected. Data on actual follow-through on a referral to an exercise-based depression treatment would be more ideal. Despite these limitations, the major strength of this study is that it is the first to assess the preferences of depressed individuals for an exercise-based treatment for depression. In addition, the sample was gender balanced and diverse in terms of income, education, and sexual orientation.

Based on the findings of this study, future qualitative and/or mixed methods studies are recommended. For example, researchers could conduct focus groups with depressed individuals prior to and/or immediately following referral to an exercise-based depression treatment to further understand the specific preferences and experiences of this population. Such a design would also allow for a quantitative analysis of how preference and demographic factors affect exercise-based depression treatment adherence and outcome.

\section{Acknowledgments}

Funding: Data collection for this study was supported by seed funding from the Centers for Behavioral and Preventive Medicine at The Miriam Hospital and a grant from the National Heart, Lung, and Blood Institute of the National Institutes of Health under award number K23-HL107391. The content is solely the responsibility of the authors and does not necessarily represent the official views of the National Institutes of Health.

\section{References}

Abrantes AM, Battle CL, Strong DR, Ing E, Dubreuil ME, Gordon A, Brown RA. Exercise Preferences of Patients in Substance Abuse Treatment. Ment Health Phys Act. 2011; 4(2):79-87. [PubMed: 22125581]

Addis ME, Mahalik JR. Men, masculinity, and the contexts of help seeking. Am Psychol. 2003; 58(1): 5-14. [PubMed: 12674814]

Andrade LH, Alonso J, Mneimneh Z, Wells JE, Al-Hamzawi A, Borges G, Kessler RC. Barriers to mental health treatment: results from the WHO World Mental Health surveys. Psychol Med. 2014; 44(6):1303-1317. [PubMed: 23931656]

Booth ML, Bauman A, Owen N, Gore CJ. Physical activity preferences, preferred sources of assistance, and perceived barriers to increased activity among physically inactive Australians. Preventive medicine. 1997; 26(1):131-137. [PubMed: 9010908] 
Carpiniello B, Primavera D, Pilu A, Vaccargiu N, Pinna F. Physical activity and mental disorders: a case-control study on attitudes, preferences and perceived barriers in Italy. Journal of mental health. 2013; 22(6):492-500. [PubMed: 24206453]

Cooney G, Dwan K, Greig CA, Lawlor DA, Rimer J, Waugh FR, Mead GE. Exercise for depression. Cochrane Database Syst Rev. 2013; 9 CD004366.

Cooney G, Dwan K, Mead G. Exercise for depression. JAMA. 2014; 311(23):2432-2433. [PubMed: 24938566]

Crone D, Johnston LH, Gidlow C, Henley C, James DV. Uptake and participation in physical activity referral schemes in the UK: an investigation of patients referred with mental health problems. Issues Ment Health Nurs. 2008; 29(10):1088-1097. [PubMed: 18853348]

Dunn AL, Trivedi MH, Kampert JB, Clark CG, Chambliss HO. Exercise treatment for depression: efficacy and dose response. American journal of preventive medicine. 2005; 28(1):1-8. [PubMed: 15626549]

Durstine, JL. American College of Sports Medicine., \& American College of Sports Medicine. ACSM's exercise management for persons with chronic diseases and disabilities. 3rd. Champaign, IL: Human Kinetics; 2009.

Ekkekakis P. Honey, I shrunk the pooled SMD! Guide to critical appraisal of systematic reviews and meta-analyses using the Cochrane review on exercise for depression as example. Mental Health and Physical Activity. 2015; 8:21-36.

Garber CE, Blissmer B, Deschenes MR, Franklin BA, Lamonte MJ, Lee IM. American College of Sports, M. American College of Sports Medicine position stand. Quantity and quality of exercise for developing and maintaining cardiorespiratory, musculoskeletal, and neuromotor fitness in apparently healthy adults: guidance for prescribing exercise. Med Sci Sports Exerc. 2011; 43(7): 1334-1359. [PubMed: 21694556]

Jones LW, Courneya KS. Exercise counseling and programming preferences of cancer survivors. Cancer practice. 2002; 10(4):208-215. [PubMed: 12100105]

Kessler RC. Epidemiology of women and depression. J Affect Disord. 2003; 74(1):5-13. [PubMed: 12646294]

Kessler RC, Bromet EJ. The epidemiology of depression across cultures. Annu Rev Public Health. 2013; 34:119-138. [PubMed: 23514317]

Kohn R, Saxena S, Levav I, Saraceno B. The treatment gap in mental health care. Bull World Health Organ. 2004; 82(11):858-866. [PubMed: 15640922]

Kroenke K, Spitzer RL, Williams JB. The PHQ-9: validity of a brief depression severity measure. J Gen Intern Med. 2001; 16(9):606-613. [PubMed: 11556941]

Lawlor DA, Hopker SW. The effectiveness of exercise as an intervention in the management of depression: systematic review and meta-regression analysis of randomised controlled trials. BMJ. 2001; 322(7289):763-767. [PubMed: 11282860]

Mathers, C.; Fat, DM.; Boerma, JT. World Health Organization. The global burden of disease : 2004 update. Geneva, Switzerland: World Health Organization; 2008.

Mohr DC, Hart SL, Howard I, Julian L, Vella L, Catledge C, Feldman MD. Barriers to psychotherapy among depressed and nondepressed primary care patients. Ann Behav Med. 2006; 32(3):254-258. [PubMed: 17107299]

Mojtabai R, Olfson M, Sampson NA, Jin R, Druss B, Wang PS, Kessler RC. Barriers to mental health treatment: results from the National Comorbidity Survey Replication. Psychol Med. 2011; 41(8): 1751-1761. [PubMed: 21134315]

Pettee Gabriel K, McClain JJ, Schmid KK, Storti KL, Ainsworth BE. Reliability and convergent validity of the past-week Modifiable Activity Questionnaire. Public Health Nutr. 2011; 14(3):435442. [PubMed: 20843404]

Prins MA, Verhaak PF, Bensing JM, van der Meer K. Health beliefs and perceived need for mental health care of anxiety and depression--the patients' perspective explored. Clin Psychol Rev. 2008; 28(6):1038-1058. [PubMed: 18420323]

Rethorst CD, Wipfli BM, Landers DM. The antidepressive effects of exercise: a meta-analysis of randomized trials. Sports Med. 2009; 39(6):491-511. [PubMed: 19453207] 
Sallis J, Saelens B. Assessment of physical activity by self-report: status, limitations, and future directions. Research Quarterly for Exercise and Sport. 2000; 71(2):1-14. [PubMed: 25680007]

Searle A, Calnan M, Lewis G, Campbell J, Taylor A, Turner K. Patients' views of physical activity as treatment for depression: a qualitative study. Br J Gen Pract. 2011; 61(585):149-156. [PubMed: 21439172]

Smith DJ, Court H, McLean G, Martin D, Langan Martin J, Guthrie B, Mercer SW. Depression and multimorbidity: a cross-sectional study of 1,751,841 patients in primary care. J Clin Psychiatry. 2014; 75(11):1202-1208. [PubMed: 25470083]

Stoutenberg M, Warne J, Vidot D, Jimenez E, Read JP. Attitudes and preferences towards exercise training in individuals with alcohol use disorders in a residential treatment setting. J Subst Abuse Treat. 2015; 49:43-49. [PubMed: 25242191]

Ussher M, Stanbury L, Cheeseman V, Faulkner G. Physical activity preferences and perceived barriers to activity among persons with severe mental illness in the United Kingdom. Psychiatric services. 2007; 58(3):405-408. [PubMed: 17325117] 


\section{Highlights}

102 depressed individuals completed an online survey

Participants reported exercise for depression preferences and barriers to exercise

The majority our depressed sample had interest in an exercise for depression program

Walking and weight lifting were the most preferred types of exercise

Symptoms of depression are seen as significant barriers to increased exercise 
Table 1

Preferences for Structure and Content of Exercise for Depression Program.

\begin{tabular}{|c|c|c|}
\hline & $\operatorname{Men}(n=47)$ & Women $(\mathbf{n}=\mathbf{5 1})$ \\
\hline \multicolumn{3}{|c|}{ Where would you like the exercise program to take place? } \\
\hline Home & $61.7 \%$ & $66.7 \%$ \\
\hline Fitness Center & $21.3 \%$ & $13.7 \%$ \\
\hline Medical Facility & $4.3 \%$ & $2.0 \%$ \\
\hline No Preference & $12.8 \%$ & $17.6 \%$ \\
\hline \multicolumn{3}{|c|}{ Would you prefer that this exercise program had you exercise } \\
\hline Alone & $68.1 \%$ & $66.7 \%$ \\
\hline In a group & $10.6 \%$ & $13.7 \%$ \\
\hline No Preference & $21.3 \%$ & $19.6 \%$ \\
\hline \multicolumn{3}{|c|}{ Would you prefer that this exercise program had you exercise } \\
\hline Without Coaching & $27.7 \%$ & $25.5 \%$ \\
\hline With Coaching & $48.9 \%$ & $51.0 \%$ \\
\hline No Preference & $23.4 \%$ & $23.5 \%$ \\
\hline \multicolumn{3}{|l|}{ Type of coaching preferred ${ }^{a}$} \\
\hline Coach physically present & $69.6 \%$ & $46.2 \%$ \\
\hline Coach present through video conferencing & $17.4 \%$ & $7.7 \%$ \\
\hline Coaching delivered through email or text & $13.0 \%$ & $46.2 \%$ \\
\hline \multicolumn{3}{|c|}{ How frequently would an ideal program ask you to exercise? } \\
\hline Multiple times per day & $6.4 \%$ & $5.9 \%$ \\
\hline Once per day & $31.9 \%$ & $17.6 \%$ \\
\hline 3-4 times per week & $40.4 \%$ & $51.0 \%$ \\
\hline $2-3$ times per week & $14.9 \%$ & $17.6 \%$ \\
\hline Once per week & $6.4 \%$ & $7.8 \%$ \\
\hline \multicolumn{3}{|c|}{ What length of exercise program would you prefer? } \\
\hline 1-4 Weeks & $12.8 \%$ & $9.8 \%$ \\
\hline 4-8 Weeks & $14.9 \%$ & $17.6 \%$ \\
\hline Longer than 8 weeks & $40.4 \%$ & $21.6 \%$ \\
\hline Until your mood improves & $31.9 \%$ & $51.0 \%$ \\
\hline \multicolumn{3}{|l|}{ What intensity do you prefer? $b$} \\
\hline Low & $17.0 \%$ & $23.5 \%$ \\
\hline Moderate & $44.7 \%$ & $25.5 \%$ \\
\hline High & $12.8 \%$ & $5.9 \%$ \\
\hline Graded & $25.5 \%$ & $45.1 \%$ \\
\hline \multicolumn{3}{|l|}{ Would you prefer to exercise } \\
\hline In one long bout (30-60 minutes) & $66.0 \%$ & $49.0 \%$ \\
\hline Shorter bouts throughout the day & $21.3 \%$ & $41.2 \%$ \\
\hline No Preference & $12.8 \%$ & $9.8 \%$ \\
\hline \multicolumn{3}{|l|}{ Preferred form of exercise } \\
\hline Walking & $27.7 \%$ & $33.3 \%$ \\
\hline
\end{tabular}




\begin{tabular}{lcc}
\hline & Men $(\mathbf{n}=\mathbf{4 7})$ & Women $(\mathbf{n}=\mathbf{5 1})$ \\
\hline Weight lifting $^{b}$ & $23.4 \%$ & $9.8 \%$ \\
Yoga $^{a}$ & $2.1 \%$ & $15.7 \%$ \\
Dance & $4.3 \%$ & $13.7 \%$ \\
\hline
\end{tabular}

$\stackrel{a}{=} p<.05$,

${ }^{b}=p<.1$, 
Table 2

Perceived Barriers to Exercise by Gender.

\begin{tabular}{lcc}
\hline & Men (n= 51) & Women (n = 51) \\
\hline Do not have enough time & $13.7 \%$ & $25.5 \%$ \\
Find it inconvenient & $21.6 \%$ & $23.5 \%$ \\
Lack motivation & $68.6 \%$ & $78.4 \%$ \\
My mood (sad, angry, etc.) & $60.8 \%$ & $68.6 \%$ \\
Too tired & $60.8 \%$ & $68.6 \%$ \\
Do not find exercise enjoyable & $25.5 \%$ & $33.3 \%$ \\
Find exercise boring & $25.5 \%$ & $19.6 \%$ \\
Lack confidence in my ability to exercise & $23.5 \%$ & $35.3 \%$ \\
Fear being injured & $17.6 \%$ & $19.6 \%$ \\
Have been injured recently & $17.6 \%$ & $15.7 \%$ \\
Lack encouragement and support from family/friends ${ }^{a}$ & $23.5 \%$ & $9.8 \%$ \\
Lack of environmental access & $5.9 \%$ & $11.8 \%$ \\
\hline$a$ \\
$p=.06$ & &
\end{tabular}

